\title{
Anaemia in HIV-Infected Children in A National Referral Hospital in Uganda: Prevalence and Associated Factors
}

\section{Mary Munyagwa ${ }^{1,2 *}$, Edison A Mworozi ${ }^{1}$, Grace Ndeezi ${ }^{1}$, Yusuf Mulumba $^{3}$ and Francis Ssali ${ }^{4}$}

${ }^{1}$ Makerere University College of health Sciences, Uganda

${ }^{2}$ Kagando Hospital, Uganda

${ }^{3}$ Uganda-CWRU Research Collaboration, Uganda

${ }^{4} J o i n t$ Clinical Research Center, Uganda

*Corresponding Author: Mary Munyagwa, Makerere University College of health Sciences and Kagando Hospital, Uganda.

DOI: 10.31080/ASMS.2020.04.0556
Received: December 27, 2019

Published: February 08, 2020

(C) All rights are reserved by Mary

Munyagwa., et al.

\begin{abstract}
Objective: Anaemia is a common complication of HIV infection affecting clinical outcome. The aim of this study was to determine the prevalence and identify factors associated with moderate to severe anaemia in HIV infected children.

Methods: This cross sectional study included 215 HIV infected children aged 6 months to 12 years. Epidemiological and clinical characteristics were recorded and a blood sample analyzed for anaemia. Multivariate logistic regression was done to determine factors associated with anaemia.

Results: Of the 215 children studied, 112 (52.1\%) were males and 103 (47.9\%) were females. The prevalence of anaemia was 50.7\% with children aged 6 to 24 months being most affected. Factors associated with anaemia were age $<60$ months (OR 4.51, p = 0.002), not taking multivitamin supplementation (OR 4.67, p = <0.001), previous transfusion (OR 3.97,p $=0.006$ ) and malaria co-infection (OR 4.42, $\mathrm{p}=0.002$ ).

Conclusions: Moderate to severe anaemia is highly prevalent among HIV infected children especially those aged 24 months and younger. HIV-infected children should be routinely evaluated for presence of anaemia, malaria prophylaxis should be stressed and more studies should be done to evaluate the impact of multivitamin supplementation on the hematological status of HIV-infected children.
\end{abstract}

Keywords: HIV-Infected; A National Referral Hospital

\section{Introduction}

Anaemia is a wide spread public health problem affecting 30 - 50\% of preschool children, highest in developing countries [1]. Anaemia is a common complication of HIV disease that negatively impacts the quality of life and clinical outcome [2].

Anaemia has been found in 1.3 to $95 \%$ of people with HIV infection $[3,4]$. Its occurrence depends on several factors such as the stage of HIV infection, sex, age, race, and concurrent illnesses. The high prevalence of iron deficiency increases the occurrence of anaemia in HIV infected children in developing countries [5-7].

Anaemia is a significant predictor of progression to AIDS [8,9]. with moderate to severe anaemia being associated with and increased risk of death among HIV infected individuals $[2,10,11]$. 
The pathogenesis of anaemia in HIV infection is multifactorial with several mechanisms occurring simultaneously in a single patient [12] However the main mechanisms include decreased red blood cell production, increased red blood cell destruction, ineffective red blood cell production and blood loss $[13,14]$ These abnormalities may be attributable to the direct effects of HIV on the bone marrow through changes in cytokine production and subsequent reduction of haemopoesis [4] and indirect effects such as, opportunistic infection, undernutrition and toxicity of therapeutic agents [15].

For adequate management, the clinical diagnosis of anaemia should be supported by laboratory determination of haemoglobin level, and investigations to a certain the cause of anaemia such as reticulocyte count, peripheral smear microscopy, mean corpuscular volume, stool examination for hookworm infestation and occult blood, and bone marrow examination. Unfortunately, the health facilities in most developing countries may not be well equipped to carry out most of these investigations.

Prior to the introduction of Anti-retro viral Therapy (ART), identified risk factors for moderate to severe anaemia among children in developing countries included hospitalization, suspected tuberculosis, malaria infection and height for age Z score $<-2$ [11].

The epidemiology of anaemia in HIV infection appears to be changing since the introduction of ART [16]. Studies have now shown that ART is effective in the treatment of anaemia in HIV infection [17] and recovery from anaemia is associated with improved survival among HIV infected patients.

This study aimed at determining the prevalence and identifying factors associated with moderate to severe anaemia among aged 6 months to 12 years admitted in the National referral hospital in Uganda.

\section{Methods}

\section{Study setting and participants}

Mulago hospital is a National referral and teaching hospital for Makerere university located in central Uganda. The hospital has a general paediatric ward where children are routinely counseled and tested for HIV using a rapid antibody test and those below 18 months who test positive, further DNA PCR is done to confirm their HIV status HIV infected children aged 6 months to 12 years pre- senting for admission to the paediatric wards in Mulago National Referral hospital were consecutively enrolled into the study.

\section{Study procedures}

Children who were HIV positive on a rapid antibody test and DNA PCR for those less than 18 months or those who were already diagnosed HIV positive were identified through a counselor who then explained to them about the study. Aclinical history and physical examination was done for each patient. Weight was measured using a $25 \mathrm{~kg}$ salter scale and length for those $<2$ years using a stadiometer while height was taken for those $>2$ years whle standing against a height board. Wasting was calculated as weight for height $\mathrm{Z}$ score of $<2 \mathrm{SD}$ and stunting as height for age $\mathrm{Z}$ score of $<2 \mathrm{SD}$. Other concurrent infections were also recorded. The WHO clinical staging of HIV disease was also done for each child.

\section{Laboratory investigations}

For each child a thick blood film for malaria and thin film for reticulocyte count were done, A complete blood count was done using an automated coulter counter which determined haemoglobin concentration, total red blood cell count, mean cell volume, mean cell haemoglobin concentration, mean cell haemoglobin, packed cell volume, red cell distribution width, white blood cell count (total and differential), and a platelet count. Absolute CD4 count and CD $4 \%$ were measured by flow cytometry using the BD FACScalibur method.

Stool microscopy to identify ova, cysts or trophozoites was done and an occult blood test was also done using a haematoccult test to identify any microscopic gastro-intestinal bleeding.

\section{Laboratory definition of anaemia}

Anaemia was defined as a haemoglobin level less than $11.0 \mathrm{~g} /$ $\mathrm{dl}$ and classified as mild for a haemoglobin between $9.0-11.0 \mathrm{~g} /$ $\mathrm{dl}$, moderate as $5.0-8.9 \mathrm{~g} / \mathrm{dl}$ and $<5 \mathrm{~g} / \mathrm{dl}$ as severe for both sexes. A heamoglobin of less than $9 \mathrm{~g} / \mathrm{dl}$ was used to define moderate to severe anaemia.

\section{Data management and analysis}

The data obtained from the participants was entered into an access database and analysed using EPI Info version 6.04 and SSPS 13 software packages. Proportions were calculated for categorical variable while mean, median and standard deviation error used to summarize the continuous variables. Chi-square P-values, odd 
ratio and 95\% confidence intervals were used to test for associations. Logistic regression was then done to determine factors independently associated with moderate to severe anaemia.

\section{Ethical considerations}

Institutional approval was obtained from Makerere College of health sciences research and ethics committee, and the National Council for Science and Technology. Informed written consent was sought from the caretakers and in addition assent was obtained from older children above 8 years who were able to sign consent before enrollment in the study. Laboratory results were availed to the attending doctors for appropriate management of the patients.

\section{Results}

\section{Characteristics of study participants}

A total of 215 HIV positive children admitted on the Paediatric wards of Mulago hospital between October 2006 and February 2007 were enrolled into the study. 112 (52.1\%) were males and 103 (47.9\%) were females, M:F 1.09: 1.115 (70.2\%) were below 60 months, 90 (41.9\%) were receiving cotrimoxazole prophylaxis, and 47 (21.9\%) were on antiretroviral therapy. 189 (87.9\%) had a biological parent/s as the primary care taker (Table 1).

\begin{tabular}{|c|c|c|}
\hline Child characteristics & $\begin{array}{l}\text { Number } \\
N=215\end{array}$ & Percentage \\
\hline \multicolumn{3}{|l|}{ Age } \\
\hline$<60$ months & 151 & 70.2 \\
\hline$\geq 60$ months & 64 & 29.8 \\
\hline \multicolumn{3}{|l|}{ Sex } \\
\hline Male & 112 & 52.1 \\
\hline Female & 103 & 47.9 \\
\hline $\begin{array}{l}\text { Child under follow up care } \\
\text { In an HIV clinic }\end{array}$ & 90 & 41.9 \\
\hline Cotrimoxazole prophylaxis & 90 & 41.9 \\
\hline Multivitamin supplementation & 70 & 32.6 \\
\hline ART & 47 & 21.9 \\
\hline \multicolumn{3}{|l|}{ Care taker characteristics } \\
\hline \multicolumn{3}{|l|}{ Primary care taker } \\
\hline Biological parent & 189 & 87.9 \\
\hline Other care taker & 26 & 12.1 \\
\hline $\begin{array}{l}\text { Mothers education level } \\
\leq \text { primary }\end{array}$ & Mothers education level & 69.8 \\
\hline > primary & 54 & 30.2 \\
\hline $\begin{array}{l}\text { Father's educational level } \\
\leq \text { primary }\end{array}$ & 49 & 45.4 \\
\hline > primary & 59 & 54.6 \\
\hline
\end{tabular}

Table 1: Baseline and social demographic characteristics.

\section{Prevalence of anaemia}

The prevalence of moderate to severe anaemia $(\mathrm{Hb}<9 \mathrm{~g} / \mathrm{dl})$ among the study population was 50.7\% (109 / 205). However overall anaemia $(\mathrm{Hb}<11 \mathrm{~g} / \mathrm{dl})$ occurred in 183/ 215 (85\%) children of whom 74 (34.4\%) had mild anaemia, 96 (44.7\%) had moderate anaemia and $13(6 \%)$ had severe anaemia. Anaemia was highest in the children less than 24 months, reduced with age until 8 years and increased after 8 years of age figure 1 .

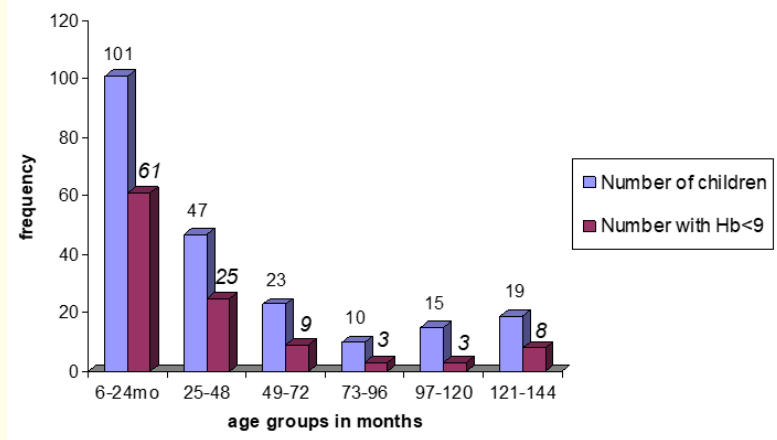

Figure 1: Age distribution of children with moderate to severe anaemia.

\section{Factors associated with moderate to severe anaemia}

On bivariate analysis, the following factors were significantly associated with moderate to severe anaemia were: age below 60 months (OR 2.86, $\mathrm{p}=0.001$ ), child newly diagnosed (OR 2.9, $\mathrm{p}<$ 0.001 ), not taking cotrimoxazole prophylaxis (OR 2.9, p < 0.001), not taking multivitamin supplementation (OR 3.27, p < 0.001), not taking ART (OR 2.13, p = 0.024), Fever more than 14 days (OR 2.68, $p=0.004)$, previous blood transfusion (OR $2.73, p=0.004)$, wasting (OR 1.75, p = 0.042), malaria coinfection (OR3.75, $p<0.001$ ) and CD 4 cell count $\%<15$ (OR 2.45, $\mathrm{p}=0.001$ ) (Table 2).

After adjusting for these factors in the multivariate logistic regression model, the following factors remained independently and significantly associated with moderate to severe anaemia: age below 60 months (adjusted OR 4.51, p = 0.002), not taking multivitamin supplementation (adjusted OR 4.67, p < 0.001), previous blood transfusion (adjusted OR 3.97, $\mathrm{p}=0.006$ ), and malaria coinfection (adjusted OR 4.42, $\mathrm{p}=0.002$ ) (Table 3).

Type of anaemia among the study participants

Microcytosis was found in 130/215 (60.5\%) of the children and 72/215 (33.5\%) had both microcytosis and RDW > 16. 104 (48.4\%) had a microcytic normochromic picture, 75/215 (34.9\%) had a normocytic normochromic picture, 26/215 (12.0\%) had a microcytic hypochromic picture. Only 6/215 (2.8\%) children had 


\begin{tabular}{|c|c|c|c|c|c|}
\hline Factor & $\begin{array}{c}\text { Mod-Severe anaemia } \\
\mathrm{Hb}<9 \mathrm{~g} / \mathrm{dl} \mathbf{n}(\%)\end{array}$ & $\begin{array}{l}\text { Mild-No naemia } \\
\mathrm{Hb} \geq 9 \mathrm{~g} / \mathrm{dl} \text { n(\%) }\end{array}$ & OR & $95 \% \mathrm{CI}$ & p-value \\
\hline Age $<60$ months & $88(58.3)$ & $63(41.7)$ & 2.86 & $1.54-5.28$ & $0.001 *$ \\
\hline Female & $53(51.5)$ & $50(48.5)$ & 1.06 & $0.62-1.81$ & 0.831 \\
\hline Newly diagnosed & $77(61.6)$ & $48(38.4)$ & 2.90 & $1.65-5.10$ & $0.000^{*}$ \\
\hline $\begin{array}{l}\text { Not taking Cotrimoxazole } \\
\text { prophylaxis }\end{array}$ & $77(61.6)$ & $48(38.4)$ & 2.90 & $1.65-5.10$ & $0.000^{*}$ \\
\hline Not taking Multivitamin & $87(60.0)$ & $58(40.0)$ & 3.27 & $1.78-5.98$ & $0.000^{*}$ \\
\hline Not taking ART & $92(54.8)$ & $76(45.2)$ & 2.13 & $1.09-4.16$ & $0.024^{*}$ \\
\hline Fever $\geq 14$ days & $43(70.5)$ & $18(29.5)$ & 2.68 & $1.37-5.27$ & $0.004^{*}$ \\
\hline Blood in stools & $9(69.2)$ & $4(30.8)$ & 2.29 & $0.68-7.69$ & $0.137^{\Psi}$ \\
\hline Previous admission & $64(55.2)$ & $52(44.8)$ & 1.47 & $0.86-2.53$ & 0.155 \\
\hline Previous blood transfusion & $32(69.6)$ & $14(30.4)$ & 2.73 & $1.36-5.48$ & $0.004^{*}$ \\
\hline Wasted (-2SD) & $54(58.7)$ & $38(41.3)$ & 1.75 & $1.01-3.03$ & $0.042^{*}$ \\
\hline WHO staging III and IV & $84(50.9)$ & $81(49.1)$ & 1.10 & $0.55-1.95$ & 0.910 \\
\hline $\begin{array}{l}\text { Immunological stage } \\
\text { CD } 4<15 \% \text { or } \\
<200(>5 \mathrm{yrs})\end{array}$ & $74(60.2)$ & 49 (39.8) & 2.45 & $1.41-4.28$ & $0.001^{*}$ \\
\hline Malaria co-infection & $33(75.0)$ & $11(25.0)$ & 3.75 & $1.77-7.90$ & $0.000^{*}$ \\
\hline
\end{tabular}

Table 2: Factors associated with moderate to severe anaemia.

$\mathrm{n}=$ number of children $\mathrm{OR}=$ Odds ratio $\mathrm{CI}=$ Confidence Interval $\mathrm{Hb}=$ haemoglobin

$\mathrm{SD}=$ standard deviation $*$ statistically significant $\mathrm{p}<0.05 \Psi=$ Fishers exact test

\begin{tabular}{|l|c|c|}
\hline Variable & $\begin{array}{c}\text { Bivariate analysis Unadjusted OR } \\
\mathbf{( 9 5 \%} \mathbf{C I}) \mathbf{p} \text {-value }\end{array}$ & $\begin{array}{c}\text { Multivariate analysis_Adjusted OR } \\
(\mathbf{9 5 \%} \text { CI) } \mathbf{p} \text {-value }\end{array}$ \\
\hline Age $<60$ months & $2.86(1.54-5.28) 0.001$ & $4.51(1.77-11.47) 0.002^{*}$ \\
\hline Not taking multivitamins & $3.27(1.78-5.98) 0.000$ & $4.67(1.97-11.06) 0.000^{*}$ \\
\hline Fever for $\geq 14$ days & $2.68(1.37-5.27) 0.004$ & $2.18(0.97-4.86) 0.056$ \\
\hline Blood in stools & $2.29(0.68-7.69) 0.137$ & $9.52(0.93-97.16) 0.057$ \\
\hline Previous transfusion & $2.08(1.36-5.48) 0.004$ & $3.97(1.47-10.68) 0.006^{*}$ \\
\hline Malaria & $3.75(1.77-7.90) 0.000$ & $4.42(1.72-11.39) 0.002^{*}$ \\
\hline CD4 < 15\% or <200 $(>5 y r s)$ & $2.45(1.41-4.28) 0.001$ & $1.67(0.74-3.76) 0.211$ \\
\hline
\end{tabular}

Table 3: Logistic regression for factors independently associated with anaemia.

macrocytosis 2 of whom were on AZT therapy and 4/215 (1.9\%)

had a normocytic hypochromic picture.

Coulter counter values were used to determine the above types according to the following values.
- $\quad$ Normocytosis MCV = 76-96 fl

- Microcytosis MCV $<76 \mathrm{fl}$

- Macrocytosis MCV $>96 \mathrm{fl}$

- $\quad$ Normochromic MCHC $=31-35 \mathrm{~g} / \mathrm{dl}$

- Hypochromic MCHC $<31 \mathrm{~g} / \mathrm{dl}$. 


\section{Stool analysis}

Stool samples were received from 164 out of 215 children. There were no ova nor cysts detected among the stool samples. Yeast cells were seen in $9.7 \%$ of the stool samples.

The occult blood test was positive in 23\% (38/164) of the children. Of the children with positive occult blood test, $76.3 \%(29 / 38)$ also had microcytosis. There was no statistically significant association between positive occult blood test and moderate to severe anaemia (OR 1.634, 95\% CI 0.78-3.41, p = 0.190).

\section{Discussion}

The prevalence of moderate to severe anaemia was $50.7 \%$. Moderate to severe anemia was independently associated with age less than 60 months, not taking multivitamin supplementation, previous blood transfusion and malaria confection. A previous study done in Uganda among children (aged 9 months to 36 months) found that $35.1 \%$ had moderate to severe anaemia [11]. The higher prevalence in this study could be explained by the fact that the present study looked at hospitalized children whose comorbidities could have increased the occurrence of anaemia while the previous study was among outpatient children.

The increasing occurrence of anaemia during adolescence also raised the overall prevalence of moderate to severe anaemia in this study.

The younger age group ( $<60$ months) was independently associated with moderate to severe anaemia. This could be explained by the fact that malaria which is a major cause of anaemia also commonly affects this age group. The increased body demands secondary to rapid physical growth in children less than 60 months, coupled with inadequate intake of nutrients also predisposes these children to anaemia especially that secondary to nutritional deficiencies. Studies in Zaire [18] and Tanzania [19] have also found anaemia to be highly prevalent in children less than 60 months and this could be due to the fact that both Tanzania and Zaire are within the malaria endemic region.

HIV infection is associated with persistent fever which results from release of proinflammatory cytokines such as TNF alpha and IL-6 which further inhibit erythropoiesis ultimately causing anaemia [20]. The association between acute malnutrition with moderate to severe anaemia in this study is similar to what others have found $[8,21,22]$. These findings suggest that the cause of anaemia in HIV infection is multifactorial, including chronic diseases and nutritional deficiencies.

As shown elsewhere [21], a previous transfusion at any point in time was also independently associated with moderate to severe anaemia in this study. This could be because after the transfusion, these children were not given haematinics to sufficiently raise their haemoglobin levels and also replenish their iron stores.

Malaria and HIV-1 are co-endemic in many developing countries with anaemia being the most common paediatric hematological manifestation of each disease [23,24]. P. falciparum malaria causes destruction of both parasitized and unparasitized red blood cells which are then sequestered by the spleen thus causing anaemia. Research has shown that HIV is associated with severe complicated malaria $[11,25,26]$. and that especially infants are at greater risk of malarial anaemia during an acute P. falciparum infection [27] leading to increased morbidity and mortality [28].

HAART improves the immune system of HIV infected children, reducing the risk of opportunistic infections, suppressing the HIV virus and ultimately reducing the risk of anaemia $[3,22]$.

The lack of an independent association of ART with anaemia could be because of the small number of children who were on ART in this study.

The oxidative stress associated with HIV infection leads to increased viral replication, quickening the progression of HIV disease and increasing the risk of HIV associated co-morbidities. This effect worsens the anaemia due to HIV its self and also that associated with inflammation and chronic disease. Multivitamins including the vitamin B group, $\mathrm{C}$, and $\mathrm{E}$ improve the immune system because of their antioxidant properties and in so doing, prevent progression of HIV infection thus reducing the risk of HIV comorbidities like anaemia [29]. Secondly the antioxidant vitamin C increases absorption of non heme iron thus reducing the risk of iron deficiency which is otherwise a major cause of anaemia in children. There are not many studies on the effect of multivitamin supplementations in HIV infected children, however multivitamins given to HIV infected pregnant women were found to reduce the occurrence of anaemia in their infants [30] 
Microcytosis was found in $60.5 \%$ of the children which is similar to what was found elsewhere $[7,9,11]$. Iron deficiency is the most likely cause of microcytosis in this study setting. A recent blood transfusion among the 27 children may have modified their morphological picture of anaemia.

The limitations of this study were that some diagnostic tests for Iron deficiency like serum ferritin were not tested, similarly other contributing factors to anaemia such as vitamin B12, folic acid deficiency and thalassaemia were not investigated. The prevalence of severe anaemia could have been underestimated because some children had received a blood transfusion prior to enrollment. The results of this study may not be generalisable because it was a hospital based study and may not represent the outpatient and rural population of HIV infected children.

\section{Conclusion}

This study established that the prevalence of moderate to severe anaemia was high among HIV infected children with those aged 6 months to 24months being most affected. Age less than 6 months, not taking multivitamin supplementation, previous blood transfusion and co-infection with malaria were significantly associated with anaemia.

HIV infected children should routinely be evaluated for the presence of anaemia. Prevention of malaria should be emphasized among HIV infected children so as to prevent anaemia due to malaria. Children who have had a blood transfusion should be given supplemental Iron to replenish their stores. More studies should be carried out to investigate the impact of multivitamin supplementation on the haematological status of HIV infected children.

\section{Acknowledgement}

We thank all the caretakers and children who participated in the study. Mr Sentongo F,Mr Ouma, Ms Nakamanya R for the excellent laboratory work.

\section{Bibliography}

1. WHO. Focusing on anaemia: Towards an integrated approach for effective anaemia control (2004).

2. Moore RD. "Human immunodeficiency virus infection, anaemia and survival". Clinical Infectious Diseases 29 (1999): 4449.
3. Belperio PS and Rhew DC. "Prevalence and outcomes of anaemia in individuals with human immunodeficiency virus: a systematic review of literature". The American Journal of Medicine 116 (2004): 27S-43S.

4. Calis JCJ., et al. "HIV-associated anaemia in children: a systematic review from a global perspective". AIDS 22 (2008): 10991112.

5. Brabin JB., et al. "Iron deficiency anaemia: reexamining the nature and magnitude of the public health problem". Journal of Nutrition 131(2001): 636S-648S.

6. Semba RD. "Iron deficiency anemia and the cycle of poverty among Human immunodeficiency virus infected women in the inner city". Clinical Infectious Diseases 37(2003): S105-11.

7. Totin D., et al. "Iron Deficiency Anaemia is Highly Prevalent among Human Immunodeficiency Virus-Infected and Un infected Infants in Uganda". Journal of Nutrition 132(2002): 423429.

8. Bachou H., et al. "Risk factors in hospital deaths in severely malnourished children in Kampala Uganda”. BMC Pediatrics 6 (2006): 7-16.

9. Eley BS., et al. "A prospective cross-sectional study of anaemia and peripheral iron status in antiretral naive ,HIV-1 infected children in Cape Town, South Africa". BMC Infectious Diseases 2(2002): 3 .

10. Mocroft A., et al. "Anaemia is an independent predictive marker for clinical prognosis in HIV-infected patients from across Europe". AIDS 13(1999): 943-950.

11. Clark TD., et al. "Risk factors and cumulative incidence of anaemia among human immunodeficiency virus-infected children in Uganda". Annals of Tropical Paediatrics Annals of Tropical Paediatrics 22(2002): 11-17.

12. Semba RD and Glenda EG. "Pathogenesis of anaemia During Human Immunodeficiency Virus Infection". Journal of Investigative Medicine 49(2001): 225-239.

13. Claster S. "Biology of Anemia, Differential Diagnosis, and Treatment Options in Human Immunodeficiency Virus Infection". The Journal of Infectious Disease 185(2002): S105-9.

14. Kreuzer K-A and Rockstroch JK. "Pathogenesis and pathophysiology of anaemia in HIV -infection". Annals of Haematology 75 (1997): 179-187. 
15. Bain BJ. "The haematological features of HIV infection". British journal of Haematology 99(1997): 1-8.

16. Volberding PA., et al. "Anemia in HIV Infection: Clinical Impact and Evidence-Based Management Strategies". Clinical Infectious Diseases 38 (2004): 1454-63.

17. Moore RD and Forney D. "Anaemia in HIV-infected patients receiving highly active antiretroviral therapy". Journal of Acquired Immune Deficiency Syndromes 29 (2002): 54-57.

18. Hedberg K., et al. "Plasmodium falciparum-associated anaemia in children at a large urban hospital in Zaire". The American Journal of Tropical Medicine and Hygiene 48 (1993): 365371.

19. Premji Z., et al. "Anaemia and plasmodium falciparum infection among young children in an holoendemic area, Bagamoyo, Tanzania". Acta Tropica 59 (1995): 55-64.

20. Moses AV., et al. "Human immunodeficiency virus infection of bone marrow endothelium reduces induction of stromal hematopoietic growth factors". Blood 87 (1996): 919-925.

21. Kahigwa E., et al. "Risk factors for presentation to hospital with severe anaemia in Tanzanian children: a case control study". Tropical Medicine and International Health 7 (2002): 823-830.

22. Shet A., et al. "Anemia and growth failure among HIV-infected children in India: a retrospective analysis". BMC Pediatrics 9 (2009): 37.

23. Van Eijik AM., et al. "Malaria and human immunodeficiecy virus infection as risk factor for anaemia in infants in Kisumu, Western Kenya". The American Journal of Tropical Medicine and Hygiene 67 (2002): 44-53.

24. Davenport GC., et al. "Haematological predictors of increased severe anaemia in Kenyan Children co-infected with plasmodium falciparum and HIV-1". American Journal of Hematology 85 (2010): 227-233.

25. Korenromp EL., et al. "Malaria Attributable to the HIV-1 Epidemic, Sub-Saharan Africa”. Emerging Infectious Diseases 11(2005): 1410-1418.

26. Laufer MK., et al. "Impact of HIV-Associated Immunosuppression on Malaria Infection and Disease in Malawi". The Journal of Infectious Diseases 193 (2006): 872-878.
27. Othieno RO., et al. "Increasing severe anaemia in HIV-1-exposed and HIV-1-positive infants and children during acute malaria". AIDS 20 (2006): 275-280.

28. Mulamba S., et al. "The effect of HIV on morbidity and mortality in children with severe malarial anaemia". Malaria Journal 6 (2007): 143.

29. Fawzi WW., et al. "A randomised trial of multivitamin supplementation and HIV disease progression and mortality". New England Journal of Medicine 351 (2004): 23-32.

30. Fawzil WW., et al. "Multivitamin supplimentation improves hematological status in HIV-infected women and their children in Tanzania". The American Journal of Clinical Nutrition 85 (2007): 1335-1343.

\section{Assets from publication with us}

- Prompt Acknowledgement after receiving the article

- Thorough Double blinded peer review

- Rapid Publication

- Issue of Publication Certificate

- High visibility of your Published work

Website: https://www.actascientific.com/

Submit Article: https://www.actascientific.com/submission.php Email us: editor@actascientific.com

Contact us: +919182824667 